\title{
Relative frequency of headache types \\ A longitudinal study in the tertiary care
}

\author{
Ariovaldo Alberto da Silva-Júnior', Bruno Engler Faleiros², \\ Tales Michel dos Santos², Rodrigo Santiago Gómez', \\ Antônio Lúcio Teixeira ${ }^{1,3}$
}

\begin{abstract}
In order to properly assess patients with primary headache, one needs to follow the cases up longitudinally. In Brazil, there were no studies using this methodology published after the publication of the latest issue of the International Classification of Headaches in 2004 ICHD-2. This is especially important when we consider that it was only after such publication that we had the criteria used to classify some types of headaches which evolve with daily, or almost daily, spells, and which are very common in tertiary health care centers. Objective: To assess the frequency of headache types in a tertiary health care center, in a longitudinal fashion. Method: We assessed 95 consecutive patients. These patients were diagnosed and classified according to the ICDH-2. The subjects were followed up for 18 months, they were treated and reassessed. Results: Most of the individuals had more than one type of headache. Among those with episodic migraine in 2007, 6 developed chronic migraine in 2008 , producing an incidence rate of $7.2 \%$. Among those with chronic migraine in 2007, 9 remitted, producing a remission rate of 75\%. In 2007, 24 individuals abused analgesic agents and 17 no longer showed abuse criteria in 2008 - when 7 new cases were found. Conclusion: The diagnosis of migraine remained stable. On the other hand, treatment brought about a reduction in the frequency of headaches caused by excessive use of analgesic, although the frequency of daily chronic headache was almost unaltered.
\end{abstract}

Key words: headache, migraine, diagnosis.

\section{Avaliação longitudinal da frequência dos tipos de cefaléia em um centro terciário}

\section{RESUMO}

Em casos de cefaléia primária é fundamental o acompanhamento longitudinal do paciente. No Brasil não há estudos que utilizaram essa metodologia após a publicação da Classificação Internacional de Cefaléias em 2004 (ICDH-2). Isso é especialmente importante quando consideramos que, apenas após tal publicação, obtivemos critérios para classificar cefaléias diárias, ou quase diárias, tão comuns em centros terciários. Objetivo: Avaliar longitudinalmente a frequência dos tipos de cefaléia em um centro de cefaléias. Método: Foram avaliados 95 pacientes consecutivos. Estes pacientes foram diagnosticados e classificados conforme a ICDH-2. Os indivíduos foram acompanhados por 18 meses, tratados e reavaliados. Resultados: A maioria dos indivíduos recebeu mais de um diagnóstico. Entre aqueles com migrânea episódica em 2007, 6 desenvolveram migrânea crônica em 2008, com 7,2\% de incidência; entre aqueles com migrânea crônica em 2007, 9 remitiram, sendo a taxa de remissão de 75\%. Em 2007, o abuso de analgésicos foi encontrado em 24 indivíduos. Desses, 17 não apresentavam mais critérios de abuso em 2008, enquanto 7 novos casos foram encontrados. Conclusão: Houve estabilidade diagnóstica da migrânea. Por outro lado, a intervenção terapêutica permitiu a redução da frequência dos casos de cefaléia por uso excessivo de analgésicos, embora a frequência de cefaléia crônica diária mostrou-se praticamente inalterada. Palavras-chave: cefaléia, migrânea, diagnóstico.

\section{Support \\ Fundação de Assistência à Pesquisa do Estado de Minas Gerais (Fapemig) and Conselho Nacional de Desenvolvimento Científico e Tecnológico (CNPq)}

Received 6 February 2010 Received in final form 30 April 2010 Accepted 7 May 2010
Headache Center, Neurology Unit, University Hospital at UFMG, Belo Horizonte MG, Brazil: ${ }^{1}$ Attending Neurologist, Neurology Unit, University Hospital at the Federal University of Minas Gerais (UFMG), Belo Horizonte MG, Brazil; ${ }^{2}$ Medical Student, School of Medicine at UFMG, Belo Horizonte MG, Brazil; ${ }^{3}$ Professor of Neurology, Department of Internal Medicine, School of Medicine at UFMG, Belo Horizonte MG, Brazil. 
Headaches affect over $50 \%$ of the adults from the general population. In this setting, tension-type headache (TTH) is the most common headache type, followed by migraine ${ }^{1,2}$. In the tertiary care, however, migraine and chronic daily headaches $(\mathrm{CDH})$, are far more common than $\mathrm{TTH}^{3-8}$. CDHs do not represent a distinct nosologic entity, as per the second edition of the International Classification of Headache Disorders (ICDH-II) ${ }^{9}$. Indeed, $\mathrm{CDHs}$ describe primary or secondary headache happening on 15 or more days per month, for at least 3 months, lasting at least 4 hours per day ${ }^{10}$.

Most studies conducted in the tertiary care are retrospective or cross-sectional ${ }^{3-7}$. Few studies followed the patients longitudinally, using the ICDH-II to diagnose the headaches. This is of particular importance for the CDHs, since diagnosis requires following the patients for at least 3 months. Furthermore, because CDHs evolve from episodic headaches, longitudinal studies are of importance in order to better understand the natural history of the primary episodic headaches. Finally, the clinical phenotype of the CDHs often incorporates aspects of migraine and of TTH, making differential diagnosis of $\mathrm{CDH}$ subtypes sometimes difficult.

Accordingly, the aim of this study was to longitudinally follow individuals with primary headache diagnoses seen at a university-based clinic, in order to classify their headaches at different years.

\section{METHOD}

This study was conducted from June of 2007 to December of 2008. Sample consists of 95 patients consecutively seen.

At the first interview, participants responded to a semistructure interview where demographic characteristics as well as the phenotype of the headaches were collected.

Patients were then diagnosed and headaches were classified according to the ICDH-II criteria. CDHs were divided in chronic migraine (CM), probable $\mathrm{CM}$, chronic TTH (CTTH), probable CTTH, chronic paroxysmal hemicrania $(\mathrm{CPH})$, new daily persistent headache, chronic post-craniotomy headache, and medication overuse headache.

After the first interview, individuals with $\mathrm{CDH}$ s were submitted to an extensive therapeutic protocol. The protocol included starting preventive medications, detoxification of offending medications when adequate, proper acute treatment, and non-pharmacological therapies.

Patients were then followed for 18 months and reassessed. Different than in the first assessment (when only the ICDH-2 diagnosis was rendered), in addition of being rediagnosed, all types of headaches presented by the participants were classified in the second assessment.

Date was entering and analyzed using software Epi-
Info ${ }^{\circ}$. The frequency of the headaches at the two assessments was compared.

\section{RESULTS}

Mean age of participants was 42.0 years, and $90.5 \%$ of them were women.

Migraine without aura was the most common diagnosis both in 2007 and 2008. In 2007, the second most common diagnosis was migraine with typical aura (29.5\%); in 2008, it was idiopathic stabbing headache (ISH), 36.8\%.

Most individuals had more than one diagnosis both in the first and in the second assessments. In 2007, 47.3\% of the participants had more than one diagnosis; in 2008, $60.0 \%$ of them had it. In 2007 a total of 147 diagnoses were rendered; in 2008, the number of diagnoses were 177. Established diagnoses are displayed in Table 1.

In the sample, $87.3 \%$ had any migraine subtype in 2007 , for a total of 83 individuals, and $86.7 \%(\mathrm{n}=82)$ in 2008. In 2007, 69 subjects had episodic migraine, and 11 had ISH. Other 12 individuals with migraine had chronic migraine, and one had ISH. Also, 2 individuals were diagnosed with probable episodic migraine.

Among individuals with episodic migraine in 2007, 5 developed chronic migraines in 2008, for an incidence of 7.2\%; of those with chronic migraine in 2007, 9 remitted to episodic migraine in 2008, for a remission rate of $75 \%$. Accordingly, considering incident and remitted cases, in 2008, 72 patients had episodic migraine and 7 had chronic migraine. Among them, 36 also had IHS.

$\mathrm{CDH}$ was diagnosed in $46.3 \%$ of the patients in 2007 , and $38.9 \%$ of the patients in 2008 , although one patient in 2007 was diagnosed with two types of $\mathrm{CDH}$ and in 2008 four patients.

In 2007, medication overuse headache was diagnosed in 24 individuals. Of them, 17 did not fill criteria for medication overuse headache in 2008, while 7 new cases were diagnosed, for a total of 14 cases in 2008. All cases of medication overuse headache happened in individuals with some migraine type.

Diagnostic subtypes of the CDHs are displayed in Table 2.

\section{DISCUSSION}

The frequency of migraine remained stable over the 18 months of follow-up. Around $87 \%$ of the patients had some form of migraine both in the first and second assessments. Other studies conducted at the tertiary care found that the prevalence of migraine at this setting ranges from 33 to $80 \%^{3-6,8}$. A past study conducted in our clinic diagnosed migraine in $79.2 \%$ of the patients ${ }^{3}$.

ISH was diagnosed in only $12.6 \%$ of the cases in the first assessment, when spontaneous report was used. However, in the second assessment, when diagnoses were 
Table 1. Established diagnosis as per for the Second Edition of the International Classification of Headache Disorders.

\begin{tabular}{|c|c|c|c|c|}
\hline \multirow[b]{2}{*}{ Diagnosis } & \multicolumn{2}{|c|}{2007} & \multicolumn{2}{|c|}{2008} \\
\hline & $\mathrm{N}$ & $\%$ & $\mathrm{~N}$ & $\%$ \\
\hline Migraine without aura & 41 & 43.2 & 43 & 45.3 \\
\hline Migraine with typical aura & 28 & 29.5 & 29 & 30.5 \\
\hline Chronic migraine & 12 & 12.6 & 7 & 7.4 \\
\hline Probable migraine without aura & 2 & 2.1 & 1 & 1.1 \\
\hline Probable chronic migraine & - & - & 2 & 2.1 \\
\hline Infrequent episodic tension type headache & - & - & 3 & 3.2 \\
\hline Frequent episodic tension type headache & 7 & 7.4 & 11 & 11.6 \\
\hline Chronic tension type headache & 5 & 5.3 & 12 & 12.6 \\
\hline Probable frequent episodic tension type headache & 1 & 1.1 & 1 & 1.1 \\
\hline Probable chronic tensional type headache & 1 & 1.1 & 3 & 3.2 \\
\hline Episodic paroxysmal hemicrania & - & - & 1 & 1.1 \\
\hline Chronic paroxysmal hemicrania & 2 & 2.1 & 2 & 2.1 \\
\hline Idiopathic stabbing headaches & 12 & 12.6 & 35 & 36.8 \\
\hline Headaches attributed to exercises & 1 & 1.1 & 1 & 1.1 \\
\hline New daily persistent headache & - & - & 1 & 1.1 \\
\hline Chronic post-craniotomy headaches & 1 & 1.1 & - & - \\
\hline Temporal arteritis & 1 & 1.1 & 1 & 1.1 \\
\hline Headaches due to Idiopathic Intracranial Hypertension & 3 & 3.2 & 3 & 3.2 \\
\hline Medication overuse headache & 24 & 25.3 & 14 & 14.7 \\
\hline Other disorders of head and face & 2 & 2.1 & 3 & 3.2 \\
\hline Trigeminal neuralgia & 2 & 2.1 & 2 & 2.1 \\
\hline Not classifiable & 2 & 2.1 & 2 & 2.1 \\
\hline
\end{tabular}

Table 2. Number of cases and relative frequency of the chronic daily headaches subtypes.

\begin{tabular}{lcccccc}
\hline \multirow{2}{*}{ Diagnoses } & \multicolumn{2}{c}{2007} & & \multicolumn{2}{c}{2008} \\
\cline { 2 - 3 } \cline { 5 - 7 } Chronic migraine & $\mathrm{N}$ & $\%$ & & $\mathrm{~N}$ & $\%$ \\
Probable chronic migraine & 12 & 26.7 & & 7 & 17 \\
Chronic tension type headache & & 0 & & 2 & 4.8 \\
Probable chronic tension type headache & 5 & 11.1 & & 12 & 29.6 \\
Chronic paroxysmal hemicrania & 1 & 2.2 & & 3 & 7.3 \\
New daily persistent headache & 2 & 4.5 & & 2 & 4.8 \\
Chronic post-craniotomy headaches & 0 & & & 1 & 2.4 \\
Medication overuse headache & 1 & 2.2 & & 0 & 0 \\
Total & 24 & 53.3 & & 14 & 34.1 \\
& 45 & 100 & & 41 & 100 \\
\hline
\end{tabular}

formally established, relative frequency was $36.8 \%$. In patients with migraine, ISH happened in $42.6 \%$ of them. Piovesan and cols., following a population of 233 individuals with migraine, found a prevalence of $40.4 \%{ }^{11}$. Raskin, found that $42 \%$ of the individuals with migraine, and only $3 \%$ of those without migraine, had ISH $^{12}$. These findings support our results.
$\mathrm{CDH}$ was similar to what has been reported in a prior study ${ }^{3}$. In studies from Europe, prevalence of $\mathrm{CDH}$ ranged from $27 \%$ to $60 \%$ at the tertiary care ${ }^{5-7}$. The diagnosis frequency had changed significantly among the $\mathrm{CDH}$ between the two assessments, although the absolute number remain relatively stable $-\mathrm{n}=45$ in 2007 and $\mathrm{n}=41$ in 2007. It is worth mentioning that the relative frequency 
of medication overuse headache decreased significantly, from $25.3 \%$ in 2007 to $14.7 \%$ in 2008 . For this CDH subtype the therapeutic protocol, which included detoxifying patients excessively using medication, was effective.

This is the first Brazilian study conducted in the tertiary care which follows patients longitudinally, applying the ICDH-II. For CDH, assessing all headache types and following patients longitudinally are of particular relevance. In cross-sectional studies it is difficult to assess all types of headache in a single patient, since these studies are often conducted with questionnaires. Furthermore, the quality of information is sometimes compromised when only one assessment is conducted. Because CDH lack biological markers, applying the ICDH-II with the support of headache diaries is necessary for formally assigning a diagnosis.

These difficulties are exemplified by medication overuse headache, which require detoxification for a definitive diagnosis. This can only be done prospectively, and after establishment of therapeutic interventions. Accordingly, we decided to only diagnose the most important headaches that patients had in 2007, to implement therapeutics, and then to diagnose all subtypes headaches.

The relative frequency of migraine diagnoses remains stable over time. Therapeutics interventions are associated with decreased frequency of medication overuse headache. The relevant frequency of the $\mathrm{CDH}$ s remained almost un- touched, suggesting that despite of all efforts, the therapeutic management of $\mathrm{CDHs}$ continues to be challenging.

\section{REFERENCES}

1. Stovner LJ, Hagen K, Jensen R, et al. The global burden of headache: a documentation of headache prevalence and disability worldwide. Cephalalgia 2007;27:193-210.

2. Queiroz LP, Peres MFP, Kowacs F, et al. Chronic daily headache in Brazil: a nationwide population-based study. Cephalalgia 2008;28:1264-1269.

3. Vasconcelos LPB, Stancioli FG, Leal JC, et al. Cefaléias em serviço especializado. Migrâneas \& Cefaléias 2006;9:4-7.

4. Felício AC, Bichuetti DB, Santos WA, Godeiro Junior CO, Marin LF, Carvalho DS. Epidemiology of primary and secondary headaches in a Brazilian tertiary-care center. Arq Neuropsiquiatr 2006;64:41-46.

5. Dowson AJ. Analysis of the patients attending a specialist UK headache clinic over a 3-year period. Headache 2003;43:14-18.

6. Gantenbein AR, Kozak S, Agosti F, Agosti R, Isler H. Headache patients in primary care and a tertiary care unit in Zürich, Switzerland. Cephalalgia 2006,26: 1451-1457.

7. Vinding GR, Zeeberg P, Lyngberg A, Nielsen RT, Jensen R. The burden of headache in a patient population from a specialized headache center. Cephalalgia 2007;27:263-270.

8. Scalas C, Calistri L. Chronic daily headache in a paediatric headache centre. J Headache Pain. 2005 Sep;6:274-276.

9. Headache Classification Committee of the International Headache Society. The International Classification of Headache Disorders, $2^{\text {nd }}$ Edition. Cephalalgia 2004;24(Suppl 1):S9-S160.

10. Silberstein SD, Lipton RB. Chronic daily headache. Curr Opin Neurol 2000; 13:277-283.

11. Piovesan EJ, Kowacs PA, Lange MC, Pacheco C, Piovesan LR, Werneck LC. Prevalence and semiologic aspects of the idiopathic stabbing headache in a migraine population. Arq Neuropsiquiatr 2001;59:201-205.

12. Raskin NH, Schwartz RK. Icepick-like pain. Neurology 1980;30:203-205 